\title{
Lack of Population Structure and Mixed Reproduction Modes in Exserohilum turcicum from South Africa
}

\author{
Maria Petronella Human, Irene Barnes, Maryke Craven, and Bridget Genevieve Crampton
}

First and fourth authors: Department of Plant and Soil Sciences, and second author: Department of Genetics, Forestry and Agricultural Biotechnology Institute, University of Pretoria, Pretoria, 0002, South Africa; and third author: Agricultural Research Council-Grain Crops Institute, Potchefstroom, 2520, South Africa.

Accepted for publication 1 June 2016.

\begin{abstract}
Human, M. P., Barnes, I., Craven, M., and Crampton, B. G. 2016. Lack of population structure and mixed reproduction modes in Exserohilum turcicum from South Africa. Phytopathology 106:1386-1392.

Exserohilum turcicum is the causal agent of northern corn leaf blight, a destructive foliar disease of maize that results in yield losses worldwide. In South Africa, typical yield losses range from 15 to $30 \%$. Previous studies found high haplotypic diversity with evidence for sexual recombination in E. turcicum populations from tropical climates such as Kenya. However, the population genetic structure and method of reproduction of E. turcicum in South Africa is unknown and, therefore, was investigated. Twelve polymorphic microsatellite markers were screened

on 258 E. turcicum isolates from maize collected during 2012 and 2013 from three maize fields in South Africa. A multiplex polymerase chain reaction assay amplifying both mating type idiomorphs was applied to investigate the distribution of mating types. No distinct genetic clusters were observed. Shared haplotypes were identified between isolates separated by distances of up to $762 \mathrm{~km}$, which provided evidence of migration. High haplotypic diversity indicated that sexual reproduction is occurring among E. turcicum isolates, although mating type ratios and linkage disequilibrium analyses did not support the hypothesis of random mating. The population genetic structure of E. turcicum in South Africa is likely due to the direct movement and spread of isolates undergoing a mixed reproductive lifecycle.
\end{abstract}

Exserohilum turcicum (Pass.) K. J. Leonard \& Suggs is the causal agent of northern corn leaf blight (NCLB), a yield-limiting foliar disease of maize, sorghum, and related grass species (Hamid and Aragaki 1975). NCLB is characterized by long, oval-shaped lesions that are gray-green to brown in color (White 1999). Yield losses occur due to loss in photosynthetic leaf material when lesions coalesce to blight the leaf surface (Kloppers and Tweer 2009). Typical yield losses range from 15 to $30 \%$ but severe infections can result in yield losses as high as 70\% (Kloppers and Tweer 2009). The life cycle of E. turcicum is closely linked to that of maize. Conidia infect young maize plants in early summer when temperatures start to increase and cause disease in susceptible plants if long dew periods, temperatures of 20 to $25^{\circ} \mathrm{C}$, humidity of 90 to $100 \%$, short photoperiods, and low luminosity prevail (Bentolila et al. 1991; Levy 1991). At the end of the growing season when maize is harvested, E. turcicum overwinters as mycelia or as conidia on infected plant debris remaining in or within close proximity to the maize field (Robert and Findley 1952). Conidia germinate at the start of the next growing season and are spread via rain splash or wind within fields or over large distances (Kloppers and Tweer 2009; Robert and Findley 1952).

E. turcicum is heterothallic and isolates of both mating types (MAT1-1 and MAT1-2) are needed to be in close proximity for sexual reproduction to occur (Luttrell 1958). The sexual stage of E. turcicum (Setosphaeria turcica) can be induced under stringent

Corresponding author: B. G. Crampton;

E-mail address: bridget.crampton@fabi.up.ac.za

*The $\boldsymbol{e}$-Xtra logo stands for "electronic extra" and indicates that one supplementary figure and one supplementary table are published online.

http://dx.doi.org/10.1094/PHYTO-12-15-0311-R

This article is in the public domain and not copyrightable. It may be freely reprinted with customary crediting of the source. The American Phytopathological Society, 2016. laboratory conditions (Luttrell 1964; Moghaddam and Pataky 1994) but is rarely observed in the field (Borchardt et al. 1998a; Bunkoed et al. 2014; Pedersen and Brandenburg 1986; Ramathani et al. 2011). The first report of sexual structures visible on diseased maize leaves in the field was from Thailand in 2014 (Bunkoed et al. 2014). Diseased maize leaves were inspected under stereo- and light microscopes for the formation of pseudothecia, which were only observed in two of nine fields from which samples were collected (Bunkoed et al. 2014).

In the absence of an observed sexual stage, two complementary approaches can be used to provide evidence for mode of reproduction in the field. First, equal frequencies of MAT idiomorphs are considered to be indicative of sexual reproduction (Bihon et al. 2014; Duong et al. 2013; Groenewald et al. 2008). Second, haplotypic diversity will be higher in sexually recombining populations than in clonal populations due to random recombination events (McDonald and Linde 2002; Milgroom 1996).

The diversity of E. turcicum isolates on maize has been studied using randomly amplified polymorphic markers (Borchardt et al. 1998a,b,c; Dong et al. 2008; Ferguson and Carson 2004, 2007). In tropical climates such as Kenya, Mexico, and Southern China, high haplotypic diversity, weak or absent linkage disequilibrium, and the presence of near-equal MAT ratios suggest frequent sexual reproduction. In temperate climates such as Europe and Northern China, linkage disequilibrium is often strong and MAT ratios skewed, indicating that sexual recombination takes place less frequently than in tropical climates (Borchardt et al. 1998a).

NCLB occurs in most maize-producing countries (Borchardt et al. 1998b), although areas in eastern and southern Africa, Latin America, China, and India are most affected (Welz and Geiger 2000). In South Africa, maize serves as the country's staple food crop. Maize is grown throughout South Africa but is mainly produced in the Free State, North West, Mpumalanga, KwaZulu-Natal, Northern Cape, and Gauteng Provinces (Courtman et al. 2012). NCLB is more prevalent in the eastern parts of South Africa, such as KwaZulu-Natal and Mpumalanga, where climatic conditions are more conducive to 
disease development, than in the drier, western parts (Kloppers and Tweer 2009). In South Africa, NCLB is currently estimated to be the most widespread and common foliar disease of maize (Kloppers and Tweer 2009). Crop rotation, fungicides, and maize cultivars resistant to NCLB are widely used in the control of this disease.

Despite the occurrence of NCLB on maize in South Africa on an annual basis, there is a lack of knowledge regarding the genetic diversity and population structure of E. turcicum in this country. Therefore, the objective of this study was to determine the population genetic structure of E. turcicum in South Africa using microsatellite markers developed previously (Haasbroek et al. 2014). An additional objective was to determine the mode of reproduction of E. turcicum isolates from the KwaZulu-Natal province of South Africa.

\section{MATERIALS AND METHODS}

Sample collection, conidial isolations, and DNA extractions. Maize leaves displaying NCLB disease symptoms were collected from three regions in KwaZulu-Natal (Cedara, Baynesfield, and Greytown) (Fig. 1). During March 2013, leaves showing NCLB symptoms were collected from maize fields in Cedara, Baynesfield, and Greytown. In these fields, four single rows were randomly selected per maize field and two leaves were sampled from 20 plants per row. One leaf was collected from each of seven maize plants from Cedara during March 2012. For the purpose of this study, a population was considered as a set of isolates occupying a single maize field over a period of time.

Isolations were made from one to three lesions per leaf or from both leaves collected per plant. NCLB lesions were surface sterilized for $30 \mathrm{~s}$ in $0.5 \%$ sodium hypochloride and rinsed twice in distilled water. To induce sporulation, NCLB lesions were excised from the leaves and placed onto sterile, moist filter paper in a petri plate that was sealed with parafilm and incubated for 4 to 7 days at $25^{\circ} \mathrm{C}$. A single conidium from each lesion was transferred onto a potato dextrose agar (PDA) (Merck) plate with a surgical needle and incubated for 10 to 15 days before DNA was extracted.

DNA was extracted from 10- to 15-day-old fungal cultures using the Zymo Research Fungal/Bacterial DNA miniprep kit (Zymo Research). Mycelia (100 to $150 \mathrm{mg}$ ) were scraped from PDA plates and DNA was extracted according to the manufacturer's protocol. DNA was eluted in $25 \mu \mathrm{l}$ of elution buffer and the concentration and quality was determined with the use of a Nanodrop 2000 spectrophotometer (Thermo Fisher Scientific). The DNA concentrations of all samples were standardized to $30 \mathrm{ng} / \mu \mathrm{l}$ for polymerase chain reactions (PCR).

Simple-sequence repeat haplotyping. Multilocus haplotypes (MLH) of the E. turcicum isolates were characterized with 13 simple-sequence repeat (SSR) loci (SSR2, SSR6, SSR10, SSR20, SSR21, SSR22, SSR23, SSR24, SSR25, SSR26, SSR27, SSR30, and SSR31), which were amplified in PCR multiplex reactions as described previously (Haasbroek et al. 2014). These markers were developed from the $S$. turcica genome strain Et28A v1.0 (Condon et al. 2013; Ohm et al. 2012). Multiplex reactions consisted of marker sets SSR20, SSR21, SSR23, and SSR26 in PCR multiplex 1A; markers SSR2, SSR6, and SSR22 in multiplex 2A; and markers SSR10, SSR24, SSR25, SSR27, SSR30, and SSR31 in multiplex 3B (Haasbroek et al. 2014).

Multiplex PCR were carried out in $20 \mu$ containing $10 \mu \mathrm{l}$ of Platinum Multiplex Mastermix (Thermo Fisher Scientific), 100 to $150 \mathrm{ng}$ of DNA, and $2 \mu \mathrm{l}$ of primer mix, consisting of equal volumes of each primer pair at optimized concentrations which ranged from 0.5 to $1.25 \mu \mathrm{M}$ (Haasbroek et al. 2014). Initial denaturation was conducted at $95^{\circ} \mathrm{C}$ for $3 \mathrm{~min}$; followed by 30 cycles of $95^{\circ} \mathrm{C}$ for $30 \mathrm{~s}$, $61^{\circ} \mathrm{C}$ for $15 \mathrm{~s}$, and $72^{\circ} \mathrm{C}$ for $1 \mathrm{~min}$; with a final extension of $60^{\circ} \mathrm{C}$ for $45 \mathrm{~min}$.

Prior to fragment analysis, $1 \mu \mathrm{l}$ of PCR multiplex $1 \mathrm{~A}$ and $1 \mu \mathrm{l}$ of PCR multiplex $2 \mathrm{~A}$ were pooled together with $8 \mu \mathrm{l}$ of sterile water to

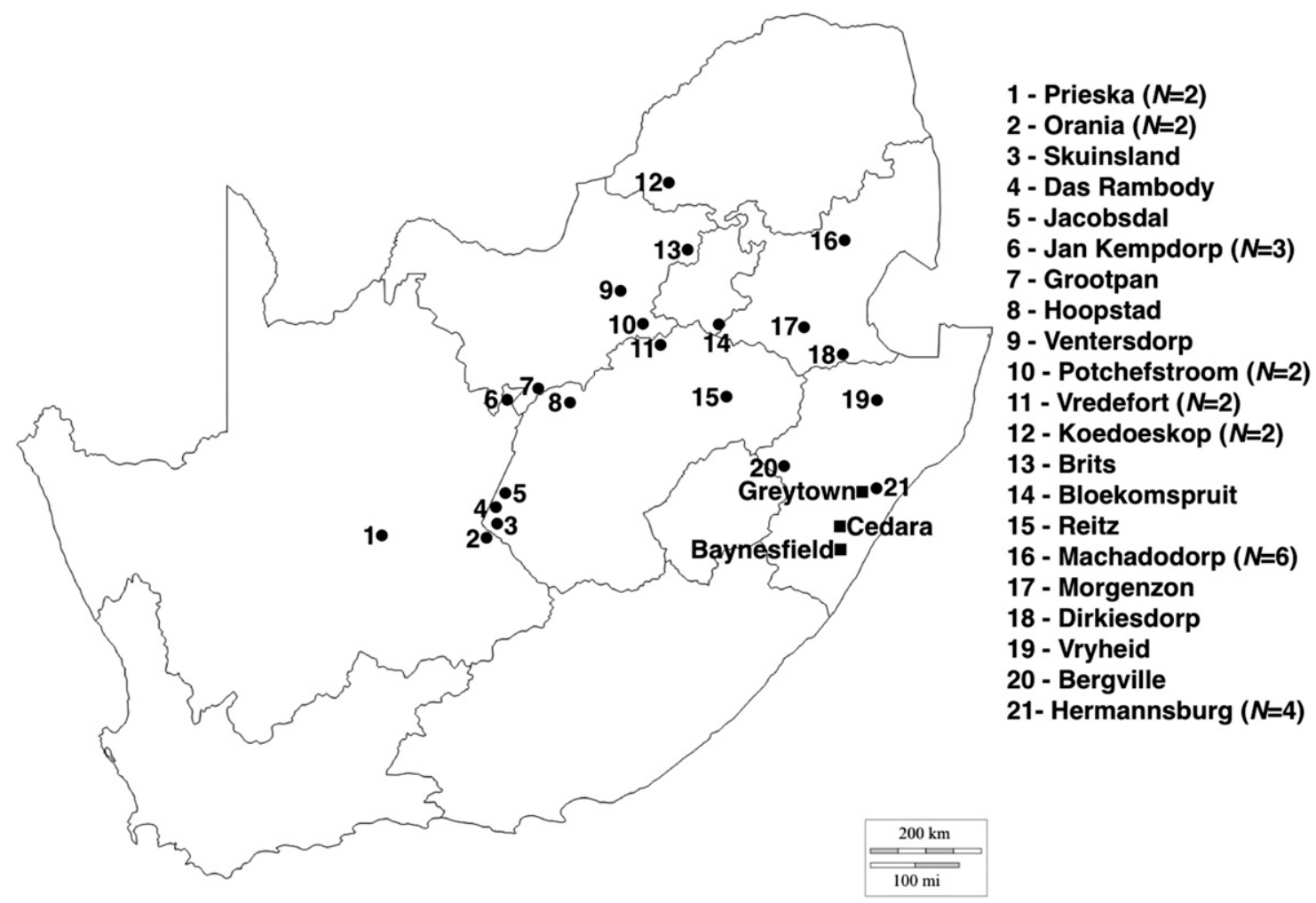

Fig. 1. Locations of maize fields in South Africa where Exserohilum turcicum isolates were sampled. Multilocus haplotypes (MLH) obtained from isolates collected during 2012 to 2013 from Cedara $(N=89)$, Baynesfield $(N=80)$, and Greytown $(N=89)$ were compared with MLH obtained from isolates collected during 2005 to 2013 from diverse regions in South Africa (1 to 21). Only one isolate was collected per sampling location, unless stated otherwise. 
a total volume of $10 \mu \mathrm{l}$. Thereafter, $1 \mu \mathrm{l}$ of the diluted product was run on a single lane on the ABI 3500xl sequencer (Thermo Fisher Scientific) using the LIZ500 (-250) (Applied Biosystems, Thermo Fisher Scientific) size standard to calibrate fragment sizes. PCR multiplex $3 \mathrm{~B}$ was diluted in a ratio of 1:9 with sterile water and run on a separate lane on the Genetic Analyzer. Alleles were scored using GENEMAPPER R software (version 4.1; Applied Biosystems, Thermo Fisher Scientific) in two panels: fragments that amplified in multiplex $1 \mathrm{~A}$ and $2 \mathrm{~A}$ were scored in panel $\mathrm{A}$ and fragments that were amplified in multiplex $3 \mathrm{~B}$ were scored in panel B.

MLH were compared between isolates from the three sampling locations to detect novel and shared haplotypes as well as private alleles that occur in one population only. The haplotypes obtained from isolates in this study were compared with haplotypes of isolates collected during 2005 to 2013 (Haasbroek et al. 2014) (Supplementary Table S1). The presence of shared haplotypes was investigated to detect migration or movement of E. turcicum isolates between locations in South Africa. Isolates from the same population that shared identical MLH were considered to be clones. A clone-corrected dataset was assembled in which each haplotype was represented once per sampling location. This dataset was used to calculate the effect of clonal propagation on population differentiation analyses. The complete (nonclone-corrected) dataset was used to determine gene and haplotypic diversity indices. Both datasets were used to determine MAT ratios and linkage disequilibrium to account for repeated resampling of the same clone.

Population differentiation. Principal coordinate analysis ( $\mathrm{PCoA})$ is a multidimensional scaling analysis to visualize similarities or dissimilarities between isolates based on the genetic distance between samples. GENALEX v. 6.501 was used to test for the presence of population subdivision (Peakall and Smouse 2012) by using Nei's unbiased genetic distance (Nei 1987), calculated between isolates, to construct the PCoA plot using the covariance-standardized method. One isolate with missing data (isolate 308a) was excluded to prevent bias in the PCoA analysis.

Hierarchical analysis of molecular variance (AMOVA) was conducted using GENALEX v.6.501 (Peakall and Smouse 2012) with 9,999 permutations to test for population subdivision within the dataset as well as differentiation between isolates from sampling locations. Pairwise comparisons of population differentiation were calculated using $\theta$ (Weir 1996), a modification of Wright's $F_{S T}$ (Wright 1978). The $\theta$ values were calculated using MULTILOCUS v. 1.31 (Agapow and Burt 2001). Obtained values were compared with 10,000 permutations, during which individuals were randomized across populations. The significance of $\theta$ values was evaluated by $P$ values $(P<0.05)$.

Gene and haplotypic diversity. The number of alleles per locus and number of polymorphic loci were determined with POPGENE v.1.32 (Yeh et al. 1997). The number of private alleles was detected with GENALEX v.6.501 (Peakall and Smouse 2012). The clonal fraction was calculated as $1-$ [(number of different haplotypes)/(total number of isolates)]. Unbiased gene diversity (Nei 1987) was determined for each population using the R package POPPR (population genetics in R) (Kamvar et al. 2014). Allelic richness (a measure of the number of alleles in a population) was determined for each population using the software ADZE (allelic diversity analyzer) v.1.0 (Szpiech et al. 2008). ADZE uses a rarefaction procedure to adjust allelic richness to the smallest population in the dataset, which was 80 isolates from Baynesfield. Comparisons of haplotypic diversity between populations were made by calculating Stoddart and Taylor's index of multilocus genotypic diversity $(G)$ (Stoddart and Taylor 1988) using POPPR (Kamvar et al. 2014). The index ranges from 1 (all MLH are the same) to the number of isolates in the dataset (all MLH are different). An additional estimate of haplotypic diversity, the Shannon index $\left(H_{s}\right)$, was calculated with the formula $H_{s}=\left[-\sum\left(p_{i} \ln p_{i}\right)\right] / \ln (N)$, where $p_{i}$ is the frequency of the $i$ th haplotype in the dataset and $N$ is the sample size (Sheldon 1969). The $H_{s}$ was determined to enable comparisons of haplotypic diversities obtained in this study to previous population genetic studies of E. turcicum (Borchardt et al. 1998a,b; Ferguson and Carson 2007). A haplotypic value of zero indicates that all isolates in the population are the same while a value of one indicates that all isolates are different. To test whether the markers sufficiently describe the level of polymorphism across samples, the mean haplotypic diversity was plotted against the number of loci in MULTILOCUS v1.31 (Agapow and Burt 2001).

Mode of reproduction. A multiplex MAT PCR assay specifically designed to amplify E. turcicum DNA was performed to determine MAT of isolates and to confirm the species identity of isolates (Haasbroek et al. 2014). PCR amplification of the MAT genes was conducted in $25 \mu \mathrm{l}$, containing $30 \mathrm{ng}$ of DNA, $2.5 \mathrm{U}$ of Bioline Taq Polymerase (Bioline), $2 \mathrm{mM} \mathrm{MgCl}_{2}$, and a mixture of the three MAT primers (MAT_1-1F, MAT_1-2F, and MAT_CommonR) (Integrated DNA Technologies) at a final concentration of $1 \mu \mathrm{M}$. Cycling conditions were $94^{\circ} \mathrm{C}$ for $2 \mathrm{~min} ; 30$ cycles of $94^{\circ} \mathrm{C}$ for $30 \mathrm{~s}$, $61^{\circ} \mathrm{C}$ for $30 \mathrm{~s}$, and $72^{\circ} \mathrm{C}$ for $1 \mathrm{~min}$; followed by a final extension step of $72^{\circ} \mathrm{C}$ for $20 \mathrm{~min}$. PCR products were separated on a $2 \%$ agarose gel (Merck) at $90 \mathrm{~V}$ for $30 \mathrm{~min}$. The MAT of each isolate was scored visually, where amplicons of 608 and 392 bp were recorded for MAT1-1 and MAT1-2, respectively. Observed ratios of the MAT idiomorphs in complete and clone-corrected datasets for each population were compared with an expected ratio of $1: 1$ for a population undergoing random mating. To test for deviations from the null hypothesis, $\chi^{2}$ tests with confidence intervals of $95 \%(P<$ $0.05)$ were used.

MULTILOCUS v.1.31 (Agapow and Burt 2001) was used to assess linkage disequilibrium among SSR loci using the index of association $\left(I_{A}\right)$ and $r$ BarD index. Tests of departure from random mating for both indices were done with 10,000 randomizations of the complete and clone-corrected MLH dataset.

Comparison with E. turcicum isolates from 2005 to 2013. The haplotypes obtained from isolates in this study were compared with haplotypes of isolates collected during 2005 to 2013 (Haasbroek et al. 2014). Only the presence of shared haplotypes was investigated to detect migration or direct movement of the pathogen between locations in South Africa.

\section{RESULTS}

E. turcicum isolates from South African maize fields. One marker, SSR10, was only polymorphic between isolates from Cedara and was excluded from any further analyses. In total, 258 isolates of E. turcicum were obtained from South African maize plants (Table 1). In total, 165 unique MLH were obtained when analyzing 12 SSR loci across 258 E. turcicum isolates from three E. turcicum populations from South Africa. The two most frequent MLH were detected 12 and 13 times and accounted for 7.27 and $7.88 \%$, respectively, of the total number of haplotypes. Singletons (MLH that were detected only once) represented $45.35 \%$ of the complete haplotype set. Cedara shared one haplotype with Baynesfield and two with Greytown. Four haplotypes were shared between Baynesfield and Greytown. Five haplotypes were shared between Cedara, Baynesfield, and Greytown.

Population differentiation. Genetic similarity was visualized among samples using PCoA, which revealed clear overlap in MLH between samples from different locations (Fig. 2). The first two axes together explained $79.91 \%$ of the genetic variability.

Hierarchical AMOVA indicated that $99 \%$ of genetic diversity was distributed within sampling locations and $1 \%$ was distributed among sampling locations. Overall population differentiation $(\Phi=$ $0.007)$ was not significant $(P=0.186)$. Pairwise comparisons (Table 2) indicated that $F_{S T}$ values between locations were nonsignificant. 
Gene and haplotypic diversity. In total, 147 alleles were detected, with the highest numbers of alleles detected in the populations from Greytown, followed by Cedara and Baynesfield (Table 1). In total, 51 private alleles were identified from the MLH. The level of clonality in each population ranged from $29 \%$ in Cedara and Greytown to $30 \%$ in Baynesfield. The levels of gene diversity in E. turcicum isolates from different sampling locations ranged from 0.516 in Baynesfield to 0.614 in Cedara and Baynesfield (Table 1). The Stoddart and Taylor index indicated a higher haplotypic diversity in Greytown (49.2) than in Baynesfield (32). The $H_{s}$ ranged from 0.87 in Baynesfield to 0.9 in Greytown. Allelic richness was highest in the collection from Greytown, followed by Cedara, and lowest in the Baynesfield collection. The plot of mean haplotype diversity versus number of loci reached a plateau at 8 loci (Supplementary Fig. S1), suggesting that the 12 loci used in this study were sufficient to describe the diversity of E. turcicum populations.

Mode of reproduction. The MAT distributions from three locations in KwaZulu-Natal revealed that MAT1-2 was observed more frequently in all populations tested (Table 3). In the samples from Baynesfield and Greytown, the observed frequencies of MAT1-1 to MAT1-2 in the complete and clone-corrected datasets differed significantly from a ratio of 1:1 expected for randomly mating populations. This is in contrast to Cedara where the null hypothesis was not rejected. The observed measures of linkage disequilibrium $\left(I_{A}\right.$ and $\left.r B a r D\right)$ calculated for the complete and clone-corrected datasets of all three sampling locations were significant and led to the rejection of the hypothesis of random mating (Table 3).

Among the leaves for which two isolates were collected from the same leaf, $57.9 \%$ of isolates from Cedara, $65.5 \%$ of isolates from Baynesfield, and $88.9 \%$ of isolates from Greytown exhibited the same MAT regardless of the MLH. In two cases from Baynesfield, two isolates that were collected from the same leaf and shared the same MLH had different MAT.
Comparison with $E$. turcicum isolates from 2005 to 2013. Shared MLH were detected between isolates from different years and geographic locations in South Africa. An isolate from Machadodorp (collected in 2012) shared the same MLH with an isolate from Ventersdorp (North West, 2011) over a distance of $350 \mathrm{~km}$. Isolates from Brits (North West) and Prieska (Free State), both collected during 2011, shared an MLH with an isolate from Greytown collected in 2013, separated by distances of 472 and $762 \mathrm{~km}$, respectively. A shared MLH was detected between an isolate from Hoopstad (Free State, 2007) and an isolate from Greytown (2013), separated by $480 \mathrm{~km}$. A shared MLH was observed between an isolate from Jan Kempdorp (Northern Cape, 2011) and two isolates collected during 2013 from Cedara (560 km) and Greytown $(580 \mathrm{~km})$.

\section{DISCUSSION}

In this study, the population structure, genetic diversity, and mode of reproduction of three populations of E. turcicum from South Africa were analyzed using 12 microsatellite markers and a multiplex MAT PCR assay. No subdivision was detected in the data set, possibly due to the proximity of locations in KwaZulu-Natal from which the majority of samples were collected or the high migration rates of E. turcicum conidia between closely located

TABLE 2. Pairwise comparisons of population differentiation among 182 Exserohilum turcicum isolates collected from three sampling locations ${ }^{\mathrm{a}}$

\begin{tabular}{lccc}
\hline Locations & Cedara & Baynesfield & Greytown \\
\hline Cedara & $\ldots$ & $0.008(0.082)$ & $-0.003(0.665)$ \\
Baynesfield & $\ldots$ & $\ldots$ & $0.009(0.074)$ \\
Greytown & $\ldots$ & $\ldots$ & $\ldots$
\end{tabular}

a The clone-corrected dataset was used to calculate pairwise $\theta$ values (Weir $1996)$ and significance levels ( $P$ values) based on 10,000 randomizations in MULTILOCUS v. 1.31 (Agapow and Burt 2001).

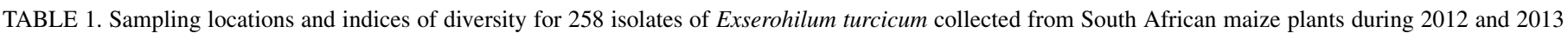

\begin{tabular}{|c|c|c|c|c|c|c|c|c|c|}
\hline Location & $\begin{array}{l}\text { Sample } \\
\text { size }\end{array}$ & $\begin{array}{l}\text { Number of unique } \\
\text { haplotypes }\end{array}$ & $\begin{array}{l}\text { Number of } \\
\text { alleles }\end{array}$ & $\begin{array}{l}\text { Number of } \\
\text { private alleles }\end{array}$ & $\begin{array}{c}\text { Allelic } \\
\text { richness }(\mathrm{SE})^{\mathrm{a}}\end{array}$ & $\begin{array}{c}\text { Clonal } \\
\text { fraction }^{\mathrm{b}}\end{array}$ & $\begin{array}{c}\text { Gene } \\
\text { diversity }^{c}\end{array}$ & $G^{\mathrm{d}}$ & $H_{s}^{\mathrm{e}}$ \\
\hline Cedara & 89 & 63 & 101 & 14 & $6.3(1.6)$ & 0.29 & 0.611 & 46.9 & 0.89 \\
\hline Baynesfield & 80 & 56 & 99 & 13 & $5.96(1.63)$ & 0.30 & 0.516 & 32 & 0.87 \\
\hline Greytown & 89 & 63 & 110 & 24 & $6.72(1.66)$ & 0.29 & 0.614 & 49.2 & 0.9 \\
\hline Total & 258 & 165 & 147 & 51 & N/A & N/A & 0.59 & 87.8 & 0.88 \\
\hline
\end{tabular}

a Allelic richness was calculated with rarefaction in ADZE to the lowest sample size of 80 (Szpiech et al. 2008) using the complete dataset. SE $=$ standard error and $\mathrm{N} / \mathrm{A}=$ not applicable.

b Clonal fraction was calculated as $1-$ [(number of different haplotypes)/(total number of isolates)].

c Nei's (1987) unbiased gene diversity $\left(G=1 / \Sigma p_{i}^{2}\right)$ was calculated in POPPR (Kamvar et al. 2014).

d Stoddart and Taylor's index $(G)$ was calculated in POPPR (Kamvar et al. 2014) using the complete dataset.

e Shannon diversity index $\left(H_{s}\right)$ was calculated with the formula $H_{s}=\left[-\sum\left(p_{i} \ln p_{i}\right)\right] / \ln (N)$ (Sheldon 1969) using the nonclone-corrected dataset.

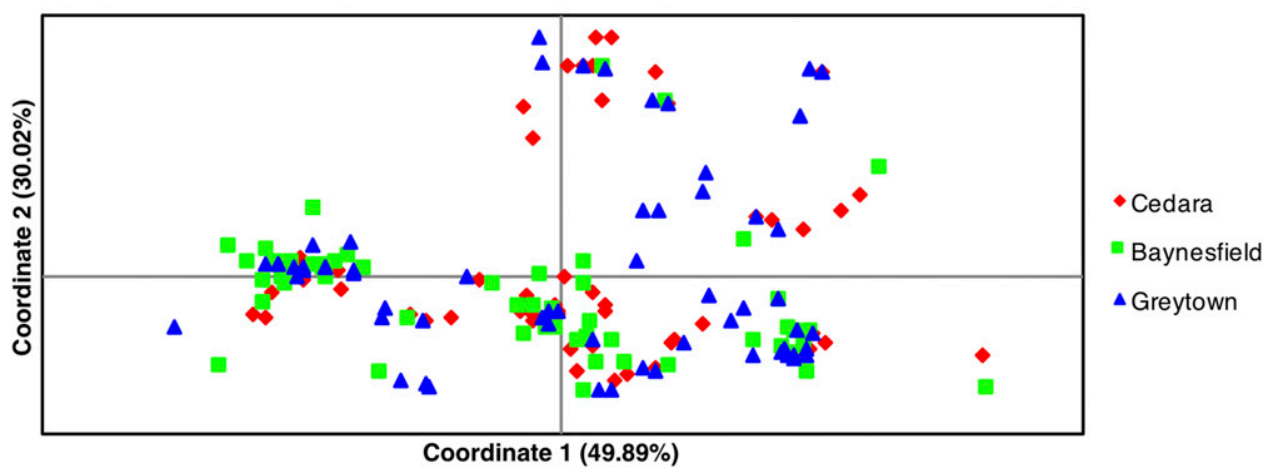

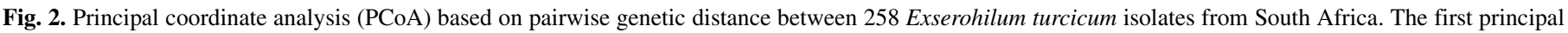
coordinate accounted for the majority of variation $(49.89 \%)$. 
maize fields. Multiple shared haplotypes were observed between isolates from sampling locations throughout South Africa, suggesting that either long-distance migration of conidia can occur or conidia can be moved directly through human-mediated movement. Although MAT ratios were skewed toward MAT1-2 and there was evidence for linkage disequilibrium, high haplotypic diversities indicate that at least some level of sexual reproduction is occurring. These findings suggest that E. turcicum isolates from South Africa undergo a mixed reproductive strategy. This is the first study to use SSR markers to investigate the population genetic structure of E. turcicum, and the first study to investigate the population structure and mode of reproduction of E. turcicum in South Africa.

Isolates collected from the same leaf did not display the same haplotype in all observed cases. This indicates that South African populations of E. turcicum from KwaZulu-Natal are diverse, and that multiple and independent infections occur on individual plants. The spread of conidia by wind or rain splash from genetically diverse sources of inoculum such as infected debris or diseased hosts is most likely responsible for heterogeneous infections on a single plant (Robert and Findley 1952).

Shared MLH were observed between three locations in KwaZuluNatal, which provides evidence for migration on a regional scale. Shared MLH between an isolate from Greytown and an isolate from the Free State Province over a distance of $762 \mathrm{~km}$ provides evidence for long-distance dispersal of E. turcicum conidia, possibly via wind (Elliott and Jenkins 1946). Previous E. turcicum population studies have shown that the same random amplified polymorphic DNA (RAPD) profile was frequently observed between isolates from the same region, such as within states of the northeastern United States or within central or western Kenya (Borchardt et al. 1998a,b,c; Dong et al. 2008; Ferguson and Carson 2004, 2007). Migration was less frequently observed between regions separated by mountains, large water masses, or areas of nonarable land, suggesting that spread occurred via windborne conidia (Borchardt et al. 1998b,c).

Observed haplotypic diversities were high in all three populations of E. turcicum from the KwaZulu-Natal Province of South Africa. The values of haplotypic diversity were too high to be associated with a strictly clonal population and provide evidence for sexual reproduction. The $H_{s}$ values obtained in this study $\left(H_{s}=0.87\right.$ to 0.9$)$ were as high as or even higher than the values obtained previously for populations of E. turcicum predicted to be undergoing sexual reproduction (Borchardt et al. 1998a,c; Ferguson and Carson 2007). Near-equal MAT ratios and absent or weak linkage disequilibrium indicated that populations from tropical climates (Kenya, Mexico, China, and the eastern United States), with $H_{s}$ of 0.79 to 0.98 , were most likely frequently undergoing sexual reproduction (Borchardt et al. 1998a,c; Ferguson and Carson 2007). Sexual reproduction was predicted to be rare in the temperate climates of Germany, Switzerland, France, and Austria based on skewed MAT ratios, strong linkage disequilibrium, and low $H_{s}$ values $\left(H_{s}=0.43\right.$ to 0.76) (Borchardt et al. 1998a).

MAT ratios indicated that sexual recombination is likely occurring frequently among isolates from Cedara but not among isolates collected from Baynesfield and Greytown. Sexual recombination among E. turcicum isolates is hypothesized to take place at the end of the season on senescing leaf material (Borchardt et al. 1998a). If this is true, subsequent clonal propagation of isolates with no or limited sexual reproduction during the maize growing season may explain unequal MAT distributions. Comparison of haplotypes from early in the growing season (lower leaves) and infections that occur later in the season (upper leaves), obtained from screening E. turcicum isolates from Kenya with RAPD markers, revealed little evidence that population structure fluctuates within a season (Borchardt et al. 1998c). Stability in the population structure throughout a single growing season suggests that sexual reproduction did not take place within that season, and may indicate mating between isolates of compatible MAT on plant debris after the maize growing season (Elliott and Jenkins 1946). Because ascospores of Fusarium graminearum produced on crop debris are the main inoculum leading to Fusarium head blight of wheat and barley (Pereyra et al. 2004), it is possible that sexual reproduction of E. turcicum also occurs on maize debris. However, the possibility that sexual reproduction takes place on an alternative host, as is the case with many rust species, cannot be excluded (Yamaoka 2014).

Linkage disequilibrium analyses do not provide support for the occurrence of random mating in the three populations of $E$. turcicum from South Africa. Factors that may lead to linkage disequilibrium include the reproductive biology of the pathogen, selection, gene flow, drift, and linkage of alleles on the same chromosomes (Milgroom 1996). Pathogen populations that undergo clonal reproduction or rare sexual reproduction events are expected to be in linkage disequilibrium. E. turcicum populations from Europe were hypothesized to mainly undergo clonal reproduction due to evidence of linkage disequilibrium in the populations sampled as well as skewed MAT ratios and low haplotypic diversity (Borchardt et al. 1998b). In pathosystems with gene-for-gene resistance, the presence of a particular resistance gene may lead to fungal isolates with the appropriate proteins to overcome this gene being favored. Maize monogenic resistance to E. turcicum exists in the form of dominant $\mathrm{Ht}$ genes (Welz and Geiger 2000), and these have been incorporated into maize hybrids by companies such as Du Pont Pioneer (Svec and Dolezal 2016) to confer resistance to E. turcicum races. Therefore, it is possible that selection for E. turcicum isolates that are able to overcome the maize resistance leads to false estimates of nonrandom associations between alleles. High levels of gene flow between populations with differing allele frequencies, genetic drift in small populations, and linkage of genes on chromosomes can also lead to false associations between alleles (Milgroom 1996).

Results from analyses of haplotypic diversity, MAT ratios, and linkage disequilibrium are inconsistent. Although MAT ratios and

TABLE 3. Mating type (MAT) ratios and tests for linkage disequilibrium of Exserohilum turcicum isolates collected from three maize-growing regions in South Africa

\begin{tabular}{|c|c|c|c|c|c|}
\hline Sampling location & MAT1-1:MAT1-2 & $P$ value ${ }^{\mathrm{a}}$ & $I_{A}{ }^{\mathrm{b}}$ & $r B a r D^{\mathrm{b}}$ & $P$ value $\left(I_{A}\right.$ and $\left.r B a r D\right)$ \\
\hline \multicolumn{6}{|l|}{ Nonclone-corrected } \\
\hline Cedara & $36: 52$ & 0.088 & 1.159 & 0.111 & $<0.0001$ \\
\hline Baynesfield & $22: 58$ & $5.7 \mathrm{E}-05$ & 1.448 & 0.143 & $<0.0001$ \\
\hline \multicolumn{6}{|l|}{ Clone-corrected } \\
\hline Cedara & $25: 38$ & 0.101 & 1.01 & 0.097 & $<0.0001$ \\
\hline Baynesfield & $16: 40$ & 0.001 & 0.955 & 0.096 & $<0.0001$ \\
\hline Greytown & $15: 48$ & $3.21 \mathrm{E}-05$ & 0.959 & 0.094 & $<0.0001$ \\
\hline
\end{tabular}

${ }^{a} P$ values based on $\chi^{2}$ analyses of MAT ratios (MAT1-1:MAT1-2). $P>0.05$ (indicated in bold) supports the hypothesis of a 1:1 MAT ratio and is indicative of a randomly mating population.

b Values of index of association $\left(I_{A}\right)$ and $r$ BarD obtained after 10,000 randomizations in MULTILOCUS v.1.31 (Agapow and Burt 2001). $P<0.05$ supports the hypothesis of linkage disequilibrium and provides evidence for nonrandom mating. 
linkage disequilibrium analyses do not provide evidence for sexual reproduction in all locations tested, the high haplotypic diversities suggest that sexual reproduction is important in the life cycle of E. turcicum populations from South Africa. In similar studies of other Dothideomycetes fungi (Cercospora sojina, $C$. beticola, and Dothistroma septosporum), high haplotypic diversity and nearequal MAT ratios were observed despite evidence for linkage disequilibrium, suggesting that these populations undergo both sexual and frequent asexual reproduction (Dale et al. 2011; Groenewald et al. 2008; Kim et al. 2013; Mullett et al. 2015). Therefore, the contradicting results between haplotypic diversity, MAT ratios, and analyses of linkage disequilibrium observed in this study may be due to mixed reproduction taking place in E. turcicum populations from South Africa.

In summary, shared MLH were detected throughout South Africa, indicating conidial dispersal over large distances. Unequal MAT distributions and linkage disequilibrium in samples are not consistent with the high haplotypic diversities observed. The findings from this study support the hypotheses that migration occurs frequently and that both sexual and asexual reproduction occur in populations of E. turcicum from South Africa.

In future, sampling from more maize production areas in South Africa will reveal with greater clarity the spatial population structure of E. turcicum. In addition, a temporal study of isolates sampled from the same field over consecutive years will aid in establishing the effect of sampling year and sampling date within a season on population structure. Comparison of haplotypes obtained from E. turcicum isolates from different host species, such as maize and sorghum, will be interesting to elucidate the genetic differences or similarities between isolates from alternative hosts. The presence of sexual structures on maize leaves, maize debris, or alternative hosts requires further investigation to elucidate the complete lifecycle of E. turcicum.

\section{ACKNOWLEDGMENTS}

We thank the Maize Trust and the University of Pretoria's Research and Development Programme for funding the research, the Genomics Research Institute at the University of Pretoria and National Research Foundation (project number SHF1207254302) of South Africa for financial support to M. Haasbroek (Human), and R. Zipfel and G. Shabangu of the sequencing facility at the University of Pretoria for technical assistance.

\section{LITERATURE CITED}

Agapow, P. M., and Burt, A. 2001. Indices of multilocus linkage disequilibrium. Mol. Ecol. Notes 1:101-102.

Bentolila, S., Guitton, C., Bouvet, N., Sailland, A., Nykaza, S., and Freyssinet, G. 1991. Identification of an RFLP marker tightly linked to the $H t 1$ gene in maize. Theor. Appl. Genet. 82:393-398.

Bihon, W., Wingfield, M. J., Slippers, B., Duong, T. A., and Wingfield, B. D. 2014. MAT gene idiomorphs suggest a heterothallic sexual cycle in a predominantly asexual and important pine pathogen. Fungal Genet. Biol. 62:55-61.

Borchardt, D. S., Welz, H. G., and Geiger, H. H. 1998a. Genetic structure of Setosphaeria turcica populations in tropical and temperate climates. Phytopathology 88:322-329.

Borchardt, D. S., Welz, H. G., and Geiger, H. H. 1998b. Molecular marker analysis of European Setosphaeria turcica populations. Eur. J. Plant Pathol. 104:611-617.

Borchardt, D. S., Welz, H. G., and Geiger, H. H. 1998c. Spatial and temporal variation of genetic marker patterns in Setosphaeria turcica populations from Kenya. J. Phytopathol. 146:451-457.

Bunkoed, W., Kasam, S., Chaijuckam, P., Yhamsoongnern, J., and Prathuangwong, S. 2014. Sexual reproduction of Setosphaeria turcica in natural corn fields in Thailand. Kasetsart J. Nat. Sci. 48:175-182.

Condon, B. J., Leng, Y., Wu, D., Bushley, K. E., Ohm, R. A., Otillar, R., Martin, J., Schackwitz, W., Grimwood, J., MohdZainudin, N., Xue, C., Wang, R., Manning, V. A., Dhillon, B., Tu, Z. J., Steffenson, B. J., Salamov, A., Sun, H., Lowry, S., LaButti, K., Han, J., Copeland, A., Lindquist, E., Barry, K., Schmutz, J., Baker, S. E., Ciuffetti, L. M., Grigoriev, I. V., Zhong, S., and Turgeon, B. G. 2013. Comparative genome structure, secondary metabolite, and effector coding capacity across Cochliobolus pathogens. PLoS Genet. 9:e1003233.

Courtman, C., van Ryssen, J. B. J., and Oelofse, A. 2012. Selenium concentration of maize grain in South Africa and possible factors influencing the concentration. S. Afr. J. Anim. Sci. 42:454-458.

Dale, A. L., Lewis, K. J., and Murray, B. W. 2011. Sexual reproduction and gene flow in the pine pathogen Dothistroma septosporum in British Columbia. Phytopathology 101:68-76.

Dong, J., Fan, Y., Gui, X., An, X., Ma, J., Dong, Z., Dong, J. G., Fan, Y. S., Gui, X. M., An, X. L., Ma, J. F., and Dong, Z. P. 2008. Geographic distribution and genetic analysis of physiological races of Setosphaeria turcica in Northern China. Am. J. Agric. Biol. Sci. 3:389-398.

Duong, T. A., De Beer, Z. W., Wingfield, B. D., and Wingfield, M. J. 2013. Characterization of the mating-type genes in Leptographium procerum and Leptographium profanum. Fungal Biol. 117:411-421.

Elliott, C., and Jenkins, M. T. 1946. Helminthosporium turcicum leaf blight of corn. Phytopathology 36:660-666.

Ferguson, L. M., and Carson, M. L. 2004. Spatial diversity of Setosphaeria turcica sampled from the Eastern United States. Phytopathology 94:892900

Ferguson, L. M., and Carson, M. L. 2007. Temporal variation in Setosphaeria turcica between 1974 and 1994 and origin of races 1,23, and 23N in the United States. Phytopathology 97:1501-1511.

Groenewald, M., Linde, C. C., Groenewald, J. Z., and Crous, P. W. 2008. Indirect evidence for sexual reproduction in Cercospora beticola populations from sugar beet. Plant Pathol. 57:25-32.

Haasbroek, M. P., Craven, M., Barnes, I., and Crampton, B. G. 2014. Microsatellite and mating type primers for the maize and sorghum pathogen, Exserohilum turcicum. Australas. Plant Pathol. 43:577-581.

Hamid, A. H., and Aragaki, M. 1975. Inheritance of pathogenicity in Setosphaeria turcica. Phytopathology 65:280-283.

Kamvar, Z. N., Tabima, J. F., and Gruenwald, N. J. 2014. Poppr: An R package for genetic analysis of populations with clonal, partially clonal, and/or sexual reproduction. PeerJ 2:e281.

Kim, H., Newell, A. D., Cota-Sieckmeyer, R. G., Rupe, J. C., Fakhoury, A. M., and Bluhm, B. H. 2013. Mating type distribution and genetic diversity of Cercospora sojina populations on soybean from Arkansas: Evidence for potential sexual reproduction. Phytopathology 103:10451051.

Kloppers, R., and Tweer, S. 2009. Northern corn leaf blight fact sheet. Online publication. PANNAR Seed (Pty) Ltd. https://www.plantwise.org/ FullTextPDF/2011/20117800335.pdf

Levy, Y. 1991. Variation in fitness among field isolates of Exserohilum turcicum in Israel. Plant Dis. 75:163-166.

Luttrell, E. S. 1958. The perfect stage of Helminthosporium turcicum. Phytopathology 48:281-287.

Luttrell, E. S. 1964. Morphology of Trichometasphaeria turcica. Am. J. Bot. $51: 213-219$.

McDonald, B. A., and Linde, C. 2002. Pathogen population genetics, evolutionary potential, and durable resistance. Annu. Rev. Phytopathol. 40:349379.

Milgroom, M. G. 1996. Recombination and the multilocus structure of fungal populations. Annu. Rev. Phytopathol. 34:457-477.

Moghaddam, P. F., and Pataky, J. K. 1994. Reactions of isolates from matings of races 1 and 23N of Exserohilum turcicum. Plant Dis. 78:767771.

Mullett, M. S., Brown, A. V., and Barnes, I. 2015. Population structure and reproductive mode of Dothistroma septosporum in the Brittany peninsula of France. Eur. J. Plant Pathol. 143:261-275.

Nei, M. 1987. Molecular Evolutionary Genetics. Colombia University Press, New York.

Ohm, R. A., Feau, N., Henrissat, B., Schoch, C. L., Horwitz, B. A., Barry, K. W., Condon, B. J., Copeland, A. C., Dhillon, B., Glaser, F., Hesse, C. N., Kosti, I., LaButti, K., Lindquist, E. A., Lucas, S., Salamov, A. A., Bradshaw, R. E., Ciuffetti, L., Hamelin, R. C., Kema, G. H. J., Lawrence, C., Scott, J. A., Spatafora, J. W., Turgeon, B. G., de Wit, P. J. G. M., Zhong, S., Goodwin, S. B., and Grigoriev, I. V. 2012. Diverse lifestyles and strategies of plant pathogenesis encoded in the genomes of eighteen Dothideomycetes fungi. PLoS Pathog. 8:e1003037.

Peakall, R., and Smouse, P. E. 2012. GenAlEx 6.5: Genetic analysis in Excel. Population genetic software for teaching and research-an update. Bioinformatics 28:2537-2539.

Pedersen, W. L., and Brandenburg, L. J. 1986. Mating types, virulence, and cultural characteristics of Exserohilum turcicum race-2. Plant Dis. 70:290-292.

Pereyra, S. A., Dill-Macky, R., and Sims, A. L. 2004. Survival and inoculum production of Gibberella zeae in wheat residue. Plant Dis. 88:724-730.

Ramathani, I., Biruma, M., Martin, T., Dixelius, C., and Okori, P. 2011. Disease severity, incidence and races of Setosphaeria turcica on sorghum in Uganda. Eur. J. Plant Pathol. 131:383-392. 
Robert, A. L., and Findley, W. R. 1952. Diseased corn leaves as a source of infection in artificial and natural epidemics of Helminthosporium turcicum. Plant Dis. Rep. 36:9-10.

Sheldon, A. L. 1969. Equitability Indices: Dependence on the Species Count. Ecology 50:466-467.

Stoddart, J. A., and Taylor, J. F. 1988. Genotypic diversity: Estimation and prediction in samples. Genetics 118:705-711.

Svec, L., and Dolezal, B. 2016. Managing northern corn leaf blight race shifts. Online publication. DuPont. https://www.pioneer.com/home/site/us/agronomy/ library/managing-nclb/

Szpiech, Z. A., Jakobsson, M., and Rosenberg, N. A. 2008. ADZE: A rarefaction approach for counting alleles private to combinations of populations. Bioinformatics 24:2498-2504.

Weir, B. S. 1996. Genetic Data Analysis II. Sinauer Associates, Inc., Sunderland, MA.
Welz, H. G., and Geiger, H. H. 2000. Genes for resistance to northern corn leaf blight in diverse maize populations. Plant Breed. 119:1-14.

White, D. G. 1999. Compendium of Corn Diseases, 3rd ed. American Phytopathological Society, St. Paul, MN.

Wright, S. 1978. Evolution and The Genetics of Populations, Vol. 4: Variability Within and Among Natural Populations. University of Chicago Press, Chicago.

Yamaoka, Y. 2014. Recent outbreaks of rust diseases and the importance of basic biological research for controlling rusts. J. Gen. Plant Pathol. 80: 375-388.

Yeh, F. C., Yang, R. C., Boyle, T., Ye, Z. H., and Mao, J. X. 1997. POPGENE: The User-Friendly Shareware For Population Genetic Analysis. Molecular Biology and Biotechnology Centre, University of Alberta, Edmonton, Alberta, Canada. 